\title{
Hereditary haemorrhagic telangiectasia (Osler-Weber-Rendu syndrome): a view from the 21 st century
}

\author{
M E Begbie, G M F Wallace, C L Shovlin
}

Postgrad Med J 2003;79:18-24

Hereditary haemorrhagic telangiectasia (HHT) affects one in 5-8000, and no longer can be viewed as solely causing anaemia (due to nasal and gastrointestinal bleeding) and characteristic mucocutaneous telangiectasia. Arteriovenous malformations commonly occur, and in the pulmonary and cerebral circulations demand knowledge of risks and benefits of asymptomatic screening and treatment. HHT is inherited as an autosomal dominant trait and there is no age cut off when apparently unaffected offspring of an individual with HHT can be told they are unaffected. This review focuses on the evolving evidence base for HHT management, issues regarding pregnancy and prothrombotic treatments, and discusses the molecular and cellular changes that underlie this disease.

See end of article for authors' affiliations

Correspondence to: Dr Claire Shovlin, Respiratory Medicine, National Heart and Lung Institute, Imperial College

Faculty of Medicine, Hammersmith Hospital, Du Cane Road, London W12 ONN, UK; c.shovlin@ic.ac.uk

Submitted 28 May 2002 Accepted 31 July 2002
$\mathrm{H}$ ereditary haemorrhagic telangiectasia (HHT, Osler-Weber-Rendu syndrome) has been subject to under-reporting for many years. Recent careful epidemiological studies in France, Denmark, and Japan, however, reveal an incidence of one in 5-8000. ${ }^{1-3}$ Individuals with HHT present to a wide range of specialties spanning medical, surgical, and general practice disciplines. Advances in medical practice mean that an expectant approach to management is no longer appropriate, and patients are increasingly aware of this through patient self help websites (see end of article). However, many specialists lack appreciation of the full range of consequences of diagnosis for patients and their families, and still view HHT as a "rare" disease, compounded by the generally poor recognition of cases.

In this article we highlight the modern view of HHT. We also cover the scientific background of a disease which features prominently in postgraduate medical examinations due to the ready availability of outpatients with classical stigmata (a recent survey indicated that HHT occurred in approximately one in 20 short case examinations for MRCP). ${ }^{4}$

\section{OVERVIEW OF HHT: THE DIFFERENCES BETWEEN 19TH CENTURY AND MODERN VIEWS OF HHT Historical view}

HHT was first recognised in the 19th century as a familial disorder causing nose bleeds, gastrointestinal bleeding, and abnormal vascular structures. $^{5-7}$ Later descriptions by Osler, Weber, and Hanes brought the disorder to the attention of the general medical community. These resulted in the eponym Osler-Weber-Rendu syndrome, ${ }^{8}$ ' though Hanes' suggestion of hereditary haemorrhagic telangiectasia ${ }^{10}$ is often preferred. The combination of nose bleeds, gastrointestinal bleeding, and iron deficiency anaemia associated with characteristic telangiectasia on the lips, oral mucosa, and fingertips (fig 1) has become firmly established as a medical entity. Yet this constitutes only "19th century HHT" (fig 2), and may not be evident in HHT patients who still have life threatening manifestations of disease.

\section{Modern view of HHT}

By the 1940s, additional abnormal vessels were being described in HHT, particularly arteriovenous malformations (AVMs) of the pulmonary, ${ }^{11}$ hepatic, ${ }^{12}$ and cerebral ${ }^{13}$ circulations. Initially it was suspected that such involvement was rare, but this was based on the frequency of symptomatic presentation to an astute practitioner. With the onset of asymptomatic screening programmes for clinical or research purposes, a much higher frequency of involvement was seen. We now estimate that at least $30 \%$ of HHT patients have pulmonary involvement, ${ }^{14}{ }^{15} 30 \%$ hepatic involvement, ${ }^{16}{ }^{17}$ and $10 \%-20 \%$ cerebral involvement. ${ }^{14}{ }^{18}$ Faced with such high figures, there is a reasoned debate regarding the extent to which these studies have overestimated risk based on screening of preselected "severe" HHT populations (that is, relatives of patients with a pulmonary $\mathrm{AVM}^{14}$ ) or screening tests with high false positive rates. ${ }^{15}{ }^{19}$ However, the figures in fig 2 provide a fair reflection of data currently available.

It is recognised that the manifestations of HHT are not present generally at birth, but develop with increasing age such that nose bleeds are usually the earliest sign of disease, often occurring in childhood, pulmonary AVMs becoming apparent from puberty, with mucocutaneous and gastrointestinal telangiectasia developing progressively with age (fig 3 ). Data suggest that by the age of 16 years, $71 \%$ of individuals will have developed some sign of HHT, rising to over $90 \%$ by

Abbreviations: AVM, arteriovenous malformation; $\mathrm{HHT}$, hereditary haemorrhagic telangiectasia; MRI, magnetic resonance imaging; TGF- $\beta$, transforming growth factor-beta 

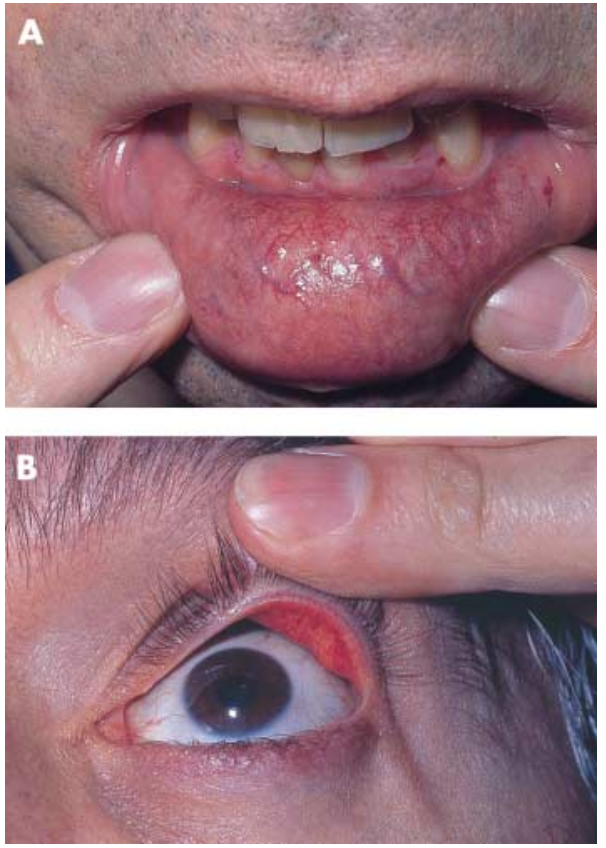

Figure 1 Classical HHT: (A) sparse telangiectasia on lips and (B) more extensive on conjunctiva.

\section{"19th century" HHT}

Telangiectasia

Nose bleeds Gastrointestinal bleeding

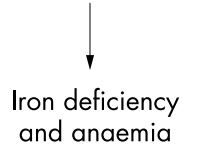

Figure 2 The changing face of HHT. The familial basis of HHT was recognised in both settings.

the age of 40 years. ${ }^{20-22}$ However these data mean that during their childbearing years, an apparently unaffected child of an HHT patient still has a $5 \%-20 \%$ chance of actually carrying the HHT disease gene.

\section{DIAGNOSIS OF HHT}

Not every individual with recurrent nose bleeds, even familial nose bleeds, will have HHT yet as indicated below, it is important that the diagnosis of HHT is considered in such cases. To

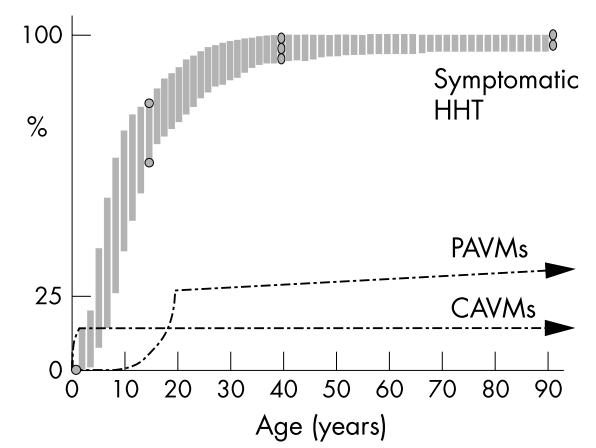

Figure 3 Age of onset of HHT features. Symptomatic HHT data points (circled) derived from references 20-22. PAVM (pulmonary AVM) and CAVM (cerebral AVM) figures highly approximated.
Box 1: The Curaçao criteria as presented in Shovlin et $\mathbf{a l}^{23 *}$

The HHT diagnosis is:

- "Definite" if three criteria are present.

- "Possible" or "suspected" if two criteria are present.

- "Unlikely" if fewer than two criteria are present.

\section{Criteria}

1. Epistaxis: spontaneous, recurrent nose bleeds.

2. Telangiectases multiple, at characteristic sites:

- Lips.

- Oral cavity

- Fingers.

- Nose.

3. Visceral lesions such as:

- Gastrointestinal telangiectasia (with or without bleeding).

- Pulmonary AVM.

- Hepatic AVM.

- Cerebral AVM.

- Spinal AVM.

4. Family history a first degree relative with HHT according to these criteria.

All offspring of an individual with HHT are at risk of having the disease since HHT may not manifest until late in life. If there is any concern regarding the presence of physical signs, an experienced physician should be ing the presence of physical signs, an experienced physician should be
consulted. Coagulation disorders should be excluded. The presence of visceral abnormalities in children should prompt a particularly careful check of other family members. These criteria are likely to be further refined as molecular diagnostic tests become available in the next few years.

* Reproduced with permission: American Journal of Medical Genetics@ 2000; Wiley-Liss Inc

permit a high level of clinical suspicion without leading to overdiagnosis, recent international consensus diagnostic criteria were developed based on the four criteria of spontaneous recurrent nosebleeds, mucocutaneous telangiectasia, visceral involvement, and an affected first degree relative. ${ }^{23}$ These define "definite HHT" where three criteria are present, "suspected HHT" with two criteria, most commonly family history and nose bleeds, or "unlikely HHT" with one criterion-for example, spontaneous nose bleeds without a family history, or a first degree relative of an HHT patient with no signs of the disease (box 1). A crucial issue for families (and medical practitioners) is that no child of a patient with HHT can be informed they do not have HHT, unless they have had a molecular diagnosis.

\section{CLINICAL FEATURES OF HHT}

\section{Nose bleeds}

Spontaneous recurrent nose bleeds from telangiectasia of the nasal mucosa are the most common clinical manifestation of HHT. While some patients will have only occasional nose bleeds, others will experience significant bleeds on a daily basis. ${ }^{24}$ Many patients require no treatment other than iron supplementation by diet and oral supplements, whereas others may require transfusions and emergency nasal packing. A number of topical, systemic, and surgical treatments are available (table 1), and in expert hands there are uncontrolled data that each appears to reduce bleeding, though responses are variable. Cauterisation is best avoided due to damage of nasal mucosa prompting vascular regrowth. The adage "to do as little as possible for as long as possible" is taking hold in HHT circles, and treatments are generally directed to patients either experiencing massive haemorrhages, or experiencing daily nose bleeds. Systemic treatments have also been introduced, and are discussed with gastrointestinal haemorrhage below. 
Table 1 Treatment options for epistaxis

\begin{tabular}{lll}
\hline Modality & Data from RCTs & Data from case reports/uncontrolled series \\
\hline $\begin{array}{l}\text { Local ablation } \\
\text { Laser: argon, Nd-YAG } \\
\text { Cauterisation }\end{array}$ & None & Short term success in expert hands ${ }^{25} 26$ \\
$\begin{array}{l}\text { Surgery } \\
\text { Septal dermatoplasty }\end{array}$ & Not recommended due to local tissue damage & \\
$\begin{array}{l}\text { Septal closure } \\
\text { Arterial ligation }\end{array}$ & None & May be beneficial ${ }^{27}$ \\
Embolisation & None & Beneficial if tolerated $^{28}$ \\
Systemic therapy & None & Case reports only, long term effects unknown \\
Oestrogen-progesterone & None & Anecdotal only : short term benefits (?<1 year) \\
Tranexamic acid and antifibrinolytics & Beneficial in heavily transfusion-dependent patients & \\
Topical therapy & None & Short term benefit and risks unknown (see debate) \\
Nasal sprays and creams & None & \\
\hline RCTs, randomised controlled trials. & &
\end{tabular}

\section{Gastrointestinal haemorrhage}

This probably contributes less frequently to iron deficiency than under-recognised nose bleeds: in many patients, improvement in nasal haemorrhage is able to significantly reduce iron and transfusion requirements. However recurrent gastrointestinal tract haemorrhage occurs in a substantial minority (up to a third) of HHT affected individuals, particularly in later years. ${ }^{20}{ }^{29}$ It often presents as an iron deficiency anaemia but occasionally as an acute gastrointestinal haemorrhage. The onset is usually from the fifth or sixth decade. Telangiectasia occur throughout the gastrointestinal tract, and are more common in the stomach or duodenum, than in the colon. They are visualised by endoscopy and are similar in size and appearance to mucocutaneous telangiectases but may be surrounded by an anaemic halo. Less commonly AVMs and aneurysms may occur, depicted by gastrointestinal angiography.

Most patients are satisfactorily managed conservatively with oral iron therapy and, if necessary, blood transfusions. Repeated laser therapy may also be used to control bleeding in the short term, though results are not as good as in the nonHHT population. ${ }^{30}$ Surgery has limited success due to recurrent disease, but may be useful for emergency control of haemorrhage from discrete lesions, as may embolisation. Antihaemorrhagic medical treatments have been sought. The only therapy supported by evidence from randomised controlled trials is the use of female hormones ( $50 \mu \mathrm{g}$ ethinyloestradiol and $\mathrm{l} \mathrm{mg}$ norethisterone) in heavily transfusiondependent patients. ${ }^{31}$ Additional manoeuvres are discussed below in the "Current debates" section.

\section{Mucocutaneous telangiectasia}

Telangiectases of the skin and buccal mucosa occur in about $75 \%$ of individuals, typically presenting later in life than epistaxis from about the third decade of life, and increasing in size and number with age. ${ }^{20}$ They mostly occur on the face, lips, tongue and buccal mucosa, and fingertips, but can occur elsewhere. They may bleed but this is rarely clinically important and the main concern is cosmetic, when short term benefits of laser or other ablation therapies may be obtained.

\section{Pulmonary AVMs}

Pulmonary AVMs are thin walled abnormal vessels that replace normal capillaries between the pulmonary arterial and venous circulations, often resulting in bulbous sac-like structures (fig 4A). They provide a direct capillary-free communication between the pulmonary and systemic circulations with three main clinical consequences:

- Pulmonary arterial blood passing through these right-toleft shunts cannot be oxygenated, leading to hypoxaemia.

- The absence of a filtering capillary bed allows particulate matter to reach the systemic circulation where it impacts in
Table 2 Complications of untreated pulmonary AVMs

\begin{tabular}{llll}
\hline Feature & Mean (\%) & Range (\%) & No of cases* \\
\hline Respiratory & 49 & $25-58$ & 260 \\
Asymptomatic & 49 & $27-71$ & 483 \\
Dyspnoea & 14 & $6-18$ & 198 \\
Chest pain & 11 & $4-18$ & 479 \\
Haemoptysis & $<1$ & $0-2$ & 192 \\
Haemothorax & 30 & $9-73$ & 275 \\
Cyanosis & 32 & $6-68$ & 267 \\
Clubbing & 49 & $25-58$ & 263 \\
Bruit & 9 & $0-25$ & 368 \\
Embolic phenomena & \multicolumn{4}{l}{} \\
Cerebral abscess & 27 & $11-55$ & 401 \\
CVA or TIA & \multicolumn{4}{l}{} \\
* Number of published cases in which frequency of feature assessed. \\
CVA, cerebrovascular accident; TIA, transient ischaemic attack. \\
\hline
\end{tabular}

other capillary beds, causing clinical sequelae particularly in the cerebral circulation.

- The fragile vessels may haemorrhage into a bronchus or the pleural cavity.

Patients with clinically silent pulmonary AVMs are still at risk of haemorrhage, and more commonly neurological sequelae due to paradoxical embolism. Catastrophic embolic cerebral events (cerebral abscess and embolic stroke), and transient ischaemic attacks occur in patients regardless of the degree of respiratory symptoms and still carry significant morbidity and mortality. Indeed, in published series of approximately 400 patients the majority of pulmonary AVM patients had no respiratory symptoms, and, only a third of affected individuals exhibited physical signs indicating a massive right-to-left shunt (cyanosis, clubbing, and polycythaemia; see table 2). ${ }^{32}$

Pulmonary AVM complications can be limited if the condition is recognised and treated, with transcatheter embolotherapy offering the safest methods of treatment. In experienced centres, there are proved long term physiological benefits of embolisation, with excellent safety profiles, and this has supported the trend towards earlier treatment of the asymptomatic patient, accompanied by clinical screening of high risk groups. In addition, prophylactic antibiotics are recommended at the time of dental and surgical procedures to reduce the risk of brain abscess (fig $4 \mathrm{~B}$ ). Screening methods vary between centres, but are based on non-invasive methods to image the pulmonary AVMs (thoracic radiography and computed tomography), or detection of the right-to-left shunt (hypoxaemia on room air and $100 \%$ fractional inspiratory oxygen, radionucleide perfusion scans or contrast echocardiography). 


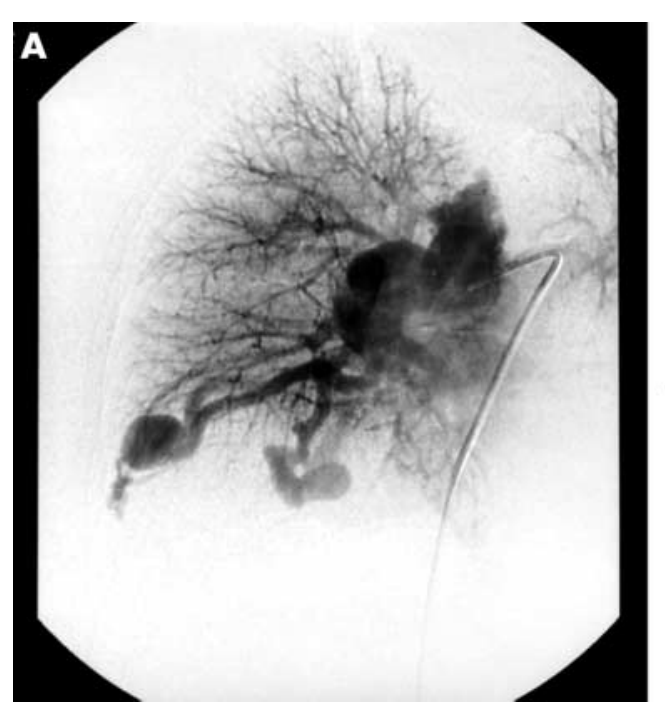

B
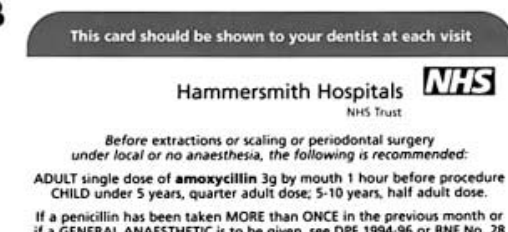

II a penicilin has been tarken MORE than ONCE in the previous month or
if a GENERAL ANAESTHETCC is to be given, see OPF 1994.96 or BNF No. 28

it a GENERAL ANAESTHETTC is to be given, see
(and subrequent dition:

For further information ring the
Respirstory Medicine Unit Hammersmith Hospita

C

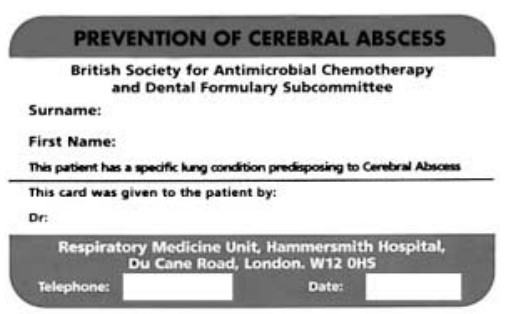

Figure 4 (A) Right lower lobe pulmonary AVMs; pulmonary angiography performed by Dr James Jackson. (B) Front and (C) back of Hammersmith Hospital pulmonary AVM antibiotic prophylaxis card.
Significant clinical concerns remain however. First, many patients with pulmonary AVMs remain under regular follow up in respiratory units without consideration of intervention. Second, published and anecdotal data suggests higher rates of complications in inexperienced hands. These include periprocedural events and long term development of systemic arterial feeders to the sac resulting in catastrophic haemorrhage, ${ }^{33}$ but this is not widely recognised. Finally, modern detection methods reveal more disease than is treatable with today's technologies and much of current management lies in the long term prevention of cerebral embolic events in patients with residual disease following maximal embolotherapy.

\section{Cerebral AVMs}

HHT patients may have cerebral involvement with telangiectases, cerebral AVMs, aneurysms, or cavernous angiomas. Most complications arise from cerebral AVMs that are thought to affect more than $10 \%$ of HHT patients. ${ }^{14}{ }^{18}$ They can lead to headache, seizures, ischaemia of the surrounding tissue due to a steal effect, or haemorrhage. Haemorrhage usually has devastating effects (significant long term morbidity after cerebral AVM rupture in the non-HHT population is quoted as $\left.53 \%-81 \%^{34}{ }^{35}\right)$, and patients with symptoms suggestive of cerebral AVMs deserve further assessment as in the non-HHT population, including non-invasive imaging and ultimately assessment by experienced neurointerventional centres. Cerebral magnetic resonance imaging (MRI) is currently the most sensitive non-invasive test, though will fail to detect a significant proportion of AVMs, and generally should not be performed in patients with pulmonary AVMs embolised with non-MRI compatible coils (the majority until the late 1990s). The question of whether asymptomatic HHT patients should be screened for cerebral AVM remains hotly debated and is discussed below.

\section{Hepatic involvement}

Silent hepatic involvement occurs in up to $30 \%$ of patients, ${ }^{16}{ }^{17}$ though symptomatic involvement is much less frequent, with fewer than 100 patients reported in worldwide series. ${ }^{36}$ When patients do present it is usually with high output heart failure, portal hypertension, or biliary disease, reflecting different patterns of vascular involvement. ${ }^{36}$ Hyperdynamic circulations, and less commonly high output cardiac failure and steal syndrome causing angina result from large AVMs between the hepatic artery and vein, causing a substantial left to right shunt. ${ }^{36}{ }^{37}$ Portal hypertension and hepatic encephalopathy particularly after gastrointestinal tract bleeding may result from shunts between the hepatic artery and portal vein, but more commonly appear to result from increased sinusoidal blood flow (that may in turn lead to increased deposition of fibrous tissue and pseudocirrhosis of the liver $\left.{ }^{36}\right)$. Hepatic AVMs, suspected by hepatomegaly, a liver bruit, or abnormal liver function tests can be diagnosed by angiography, computed tomography, MRI, or Doppler sonography. ${ }^{38}$

The treatment of hepatic AVMs has changed in the last two to three years. Embolisation of feeding vessels used to be performed but after several cases of fatal hepatic necrosis, HHT physicians in the United States have placed a moratorium on this treatment unless supported by a liver transplantation programme..$^{39}$ In the rare cases when acute hepatic failure develops, liver transplantation may be life saving. ${ }^{40}$

\section{HOW TO MANAGE THE HHT PATIENT}

The majority of patients with HHT will still effectively have "19th century" HHT, experiencing only nose bleeds, mucocutaneous telangiectasia, and a tendency to iron deficiency anaemia. For HHT patients who do not present spontaneously to medical practitioners before the age of 60 years, there is no excess mortality. ${ }^{3}$ However, there is significant morbidity and mortality in younger patients, predominantly attributed to the consequences of visceral involvement, particularly pulmonary and cerebral involvement leading to early onset strokes and brain abscess.

General principles of HHT management are illustrated in box 2 overleaf.

\section{Special circumstances and debated topics in HHT \\ The pregnant HHT patient}

Pregnancy poses a risk to a small proportion of women with HHT, and individual patients may need to be cautioned against pregnancy on a case-by-case basis. However, for the majority of patients, pregnancy is uneventful. The patient should be aware that any offspring will have a 50\% risk of inheriting HHT, that there may be complications due to enlargement of pulmonary AVMs, and that as spinal AVMs affect perhaps as many as $1 \%-2 \%$ of HHT patients, many anaesthetists will not perform epidural analgesia for HHT mothers unless MRI scans have excluded this possibility. Otherwise, anecdotal data suggests nose bleeds may get worse, and skin telangiectasia become more prominent, with no firm data regarding effects on hepatic and cerebral AVMs.

Medical practitioners should be aware that any pulmonary AVMs will enlarge during pregnancy, and fatal haemorrhage from maternal pulmonary AVMs has been described. ${ }^{41}$ Women with HHT should be screened for pulmonary AVMs and treated maximally before pregnancy, though treatment may 
be safely undertaken in late pregnancy if required ${ }^{42}$ Any haemoptysis should be seen as a medical emergency and prompt immediate admission.

\section{Should asymptomatic patients be screened for cerebral AVMs?}

The question of whether asymptomatic HHT patients should be screened for cerebral AVMs remains hotly debated since diagnostic and interventional modalities carry significant risks, and many believe cerebral AVMs identified in an asymptomatic HHT population by screening to have a lower rate of haemorrhage than those in other populations. ${ }^{43}$ The North American and European management approaches to individuals with HHT differ markedly. Many centres in North America advocate and practice screening of HHT neonates, whereas screening is not performed in the majority of European centres. This is a difficult issue in patient management as many patients will access US based websites. However, all patients should be aware that the risk-benefit of asymptomatic screening is by no means clear cut and remains the subject of intense scrutiny on both sides of the Atlantic.

\section{How safe is it to use hormones and antifibrinolytics to} modify the haemorrhagic phenotype?

In a double blind randomised controlled trial, $50 \mu \mathrm{g}$ ethinyloestradiol and $\mathrm{l} \mathrm{mg}$ norethisterone resulted in a significant reduction in transfusion requirements in 10 patients with a mean transfusion requirement of 19.4 packed cells units per year. ${ }^{31}$ These data have been extrapolated in clinical practice to patients with lesser degrees of haemorrhage not necessarily associated with regular transfusion requirements. The use of higher dose conjugated oestrogens in the "hormone replacement" range of over $625 \mu \mathrm{g}$ ethinyloestradiol equivalent, or prothrombotic agents such as tranexamic acid $^{44}$ and aminocaproic acid ${ }^{45}$ are also widespread in management of HHT related bleeding, though not supported by data from randomised controlled trials. However, it should be remembered that HHT patients are at risk of thromboembolic disease, ${ }^{46}$ and in our experience there is concern that these practices may increase the risk of thrombotic events in HHT patients.

\section{How safe is it to ascribe unusual presentations to rare complications of HHT?}

As potential complications of HHT become better appreciated, there is the genuine concern that HHT patients may not undergo the full range of diagnostic investigations for particular clinical presentations. It is crucial that assessments are based on an appreciation of the likely frequency of HHT-associated complications, and possible non-HHT aetiologies also considered. This is particularly true when a possible extremely rare complication of HHT such as severe chest pain, pulmonary hypertension, ${ }^{47}$ or hepatic failure is under consideration. Even for lower gastrointestinal bleeding, at least one colonoscopy to exclude a malignant aetiology is usually warranted.

\section{MOLECULAR AND CELLULAR BASIS OF HHT}

HHT is inherited as an autosomal dominant trait with varying penetrance and expressivity. Mutations in two genes, endoglin and $A L K-1$, have been shown to be responsible for HHT, with the disease subtypes designated HHTI and HHT2, respectively. The search for a third disease locus in families shown to map to neither of these loci is ongoing ${ }^{48}$ Confirmation that endoglin mutations are causative is available from experiments in transgenic mice. Some mice carrying one normal and one mutated copy of the endoglin gene (that is, endoglin ${ }^{+/}$heterozygotes) display features of HHT. ${ }^{49}$

Endoglin and $A L K-1$ encode proteins expressed on vascular endothelial cells. Most gene products resulting from HHTcausing mutations in these genes are unstable at the level of

\section{Box 2: Key points}

\section{General}

- HHT is one of the commonest monogenic diseases with an incidence of one in 5-8000.

- Due to late onset penetrance, no child of an HHT affected parent should be told they do not have HHT, unless there is a molecular diagnosis.

\section{Risks}

- The 19th century view of HHT as a condition of nose bleeds and gastrointestinal bleeding is no longer appropriate.

- Catastrophic strokes occur in the HHT population due to usually silent pulmonary and cerebral AVMs.

- Pulmonary AVMs can be safely detected and treated-all HHT patients should be screened for pulmonary AVMs and treated with prophylactic antibiotics and embolisation.

- Asymptomatic screening for cerebral AVMs remains the subject of debate because of the risks of diagnostic and treatment modalities, and unclear natural history.

\section{Management}

- Suspect underlying HHT in all patients with pulmonary AVMs, brain abscess, or early onset stroke.

- Manage nose bleeds, gastrointestinal bleeding, and other visceral involvement symptomatically by appropriate specialists.

- Screen all HHT patients for pulmonary AVMs, even when entirely asymptomatic, and arrange for treatment by an experienced centre if detected.

- Educate patients (and medical practitioners) that screening for other manifestations such as cerebral or hepatic involvement is the subject of intense debate and is currently not offered in the UK.

- Do not forget non-HHT pathology in HHT patients.

mRNA or protein, and it has been shown that endothelial cells derived from HHT1 or HHT2 patients express approximately one half of the normal endoglin or ALK-1 levels, respectively. ${ }^{50}$ Therefore it is believed that in most if not all cases, HHT results from endoglin or ALK-1 haploinsufficiency-that is, lack of sufficient protein for normal function. As endothelial cells derived directly from arteriovenous malformations also express half the normal levels of endoglin, these malformations do not appear to be due to an additional local loss of endoglin expression due to a "second hit". ${ }^{2}$

How do mutations in endoglin and ALK-1 result in HHT? These genes encode proteins that are involved with signalling by the transforming growth factor-beta (TGF- $\beta$ ) superfamily. This group of peptide growth factors includes TGF- $\beta$ s, activins, and the bone morphogenetic proteins, which affect cellular growth and differentiation through signal transduction cascades from transmembrane receptor complexes (for review, see Heldin et $a l^{53}$ ). Generally, type II TGF- $\beta$ receptors bind the ligand directly, recruit and activate type I receptors that activate downstream cytoplasmic signalling molecules including SMADs. SMADs then bind into complexes and translocate to the nucleus, where they modulate the expression of target genes through direct binding to DNA.

As ALK- 1 is a TGF- $\beta$ superfamily type I receptor, and endoglin associates with different signalling receptors and can modify TGF- $\beta 1$ signalling, it is expected that the abnormal vessels in HHT develop because of aberrant TGF- $\beta$ signalling at some stage during vascular development and homoeostasis. Endoglin and ALK-1 may work together to play specific parts in governing cellular responses such as proliferation and adhesion induced by members of the TGF- $\beta$ superfamily. As other HHT disease genes are identified, these will also likely play a part in this signalling pathway possibly either as ligands, receptors, or downstream transducers of TGF- $\beta$ family member signals. 


\section{Box 3: Self help websites}

- UK Telangiectasia Self Help Group: http://www. telangiectasia.co.uk and email info@telangiectasia.co.uk

- HHT Foundation International: http://www.hht.org. This highly informative website offers advice that is sometimes more applicable for North American than European health care, particularly with regard to cerebral AVM screening

However, understanding whether patients have endoglin or ALK-1 mutations does not allow a strong prediction of the likely course of HHT since all features of HHT can be seen in both HHTl and HHT2. The different pattern of disease in different members of the same families in man (and in the mouse models) suggest that other genetic and environmental influences modify the HHT phenotype. Understanding these modifications will be critical to furthering our understanding of the development of the vascular lesions in HHT, and may help our understanding of the pathways by which normal vascular integrity is maintained.

\section{ACKNOWLEDGEMENTS}

We thank Dr James Jackson FRCR, MRCP for performing the pulmonary angiogram illustrated in fig 4A, and Mr William Grant FRCS, for helpful comments on the manuscript.

\section{MULTIPLE CHOICE QUESTIONS (TRUE (T)/FALSE (F); ANSWERS AT END OF REFERENCES)}

\section{Q1. Hereditary haemorrhagic telangiectasia (HHT)} Osler-Weber-Rendu syndrome:

(A) Affects approximately one in 100000 individuals

(B) Can be safely ignored in the patient who just has nose bleeds

(C) Is only life threatening with a patient with nose bleeds and facial telangiectasia

(D) Does not influence mortality in epidemiological studies of the over 60 s

(E) Frequently causes early onset strokes

\section{Q2. A child of an individual with HHT:}

(A) Can be told they do not have HHT if they show no manifestation of the disease by the age of 30

(B) Has a one in two chance of developing HHT

(C) If develops HHT, is likely to have the same type of HHT as their parent

(D) Has definite HHT if they develop nose bleeds

(E) Does not require medical review if they do not have nose bleeds

Q3. An individual with HHT complains of feeling generally unwell. Possible diagnoses to consider are:
(A) Anaemia
(B) Hypoxaemia
(C) Recent onset stroke
(D) Liver disease
(E) Transient ischaemic attacks

Q4. Patients who are fit and well with HHT should be screened for:
(A) Gastrointestinal telangiectasia
(B) Pulmonary AVMs
(C) Cerebral AVMs
(D) Hepatic AVMs
(E) Spinal AVMs

\section{Q5. The science of HHT:}

(A) HHT develops in the presence of only a single abnormal mutated gene

(B) The genes mutated in HHT are implicated in signalling by fibroblast growth factor

(C) The genes mutated in HHT allow prediction of the pattern of HHT in the individual

(D) No environmental modifiers of HHT have been found to date

(E) The disease genes in HHT are likely to be the only genetic factors influencing the HHT phenotype

\section{Authors' affiliations}

M E Begbie, C L Shovlin, Respiratory Medicine, National Heart and Lung Institute, Imperial College Faculty of Medicine, Hammersmith Hospital, London

G M F Wallace, Respiratory Medicine, Rayne Laboratories, University of Edinburgh

\section{REFERENCES}

1 Bideau A, Plauchu $\mathrm{H}$, Brunet $\mathrm{G}$, et al. Etude épidémiologique de la maladie de Rendu-Osler disease en France. Population 1989;1:9-28.

2 Dakeishi M, Shioya T, Wada Y, et al. Genetic epidemiology of hereditary haemorrhagic telangiectasia in a local community in the northern part of Japan. Hum Mutat 2002;19:140-8.

3 Kieldsen AD, Vase P, Green A. Hereditary hemorrhagic telangiectasia (HHT): a population-based study of prevalence and mortality in Danish HHT patients.J Intern Med 1999.245:31-9.

4 Ryder REJ, Mir MA, Freeman EA. An aid to the MRCP short cases. Oxford: Blackwell Scientific, 1986.

5 Sutton HG. Epistaxis as an indication of impaired nutrition, and of degeneration of the vascular system. Medical Mirror 1864;1:769-81.

6 Legg W. A case of haemophilia complicated with multiple naevi. Lancet 1876 ;ii:856-7.

7 Rendu H. Epistaxis repetees chez un sujet porteur de petits angiomes cutanes et muquez. Gazette des Hopitaux Civils et Militaires (Paris) 1896; 135:1322-3

8 Osler W. On a family form of recurring epistaxis, associated with multiple telangiectases of the skin and mucous membranes. Bulletin of the Johns Hopkins Hospital 1901;12:333-7.

9 Weber F. Multiple hereditary developmental angiomata (telangiectases) of the skin and mucous membranes associated with recurring haemorrhages. Lancet 1907;ii: 160-2.

10 Hanes FM. Multiple hereditary telangiectases causing hemorrhage (hereditary hemorrhagic telangiectasia). Bulletin of the Johns Hopkin Hospital 1909:20(216):63-73.

11 Rundles RW. Hemorrhagic telangiectasia with pulmonary artery aneurysm: case report. Am J Med Sci 1945;210:76-81.

12 Smith JL, Lineback MI. Hereditary hemorrhagic telangiectasia; nine cases in one negro family with special reference to hepatic lesions. Am J Med 1954;17:41-9.

13 Román G, Fisher M, Perl DP, et al. Neurological manifestations of hereditary hemorrhagic telangiectasia (Rendu-Osler-Weber disease): report of 2 cases and review of the literature. Ann Neurol 1978:4:130-44.

14 Haitjema T, Disch F, Overtoom TTC, et al. Screening family members of patients with hereditary haemorrhagic telangiectasia. Am J Med 1995;99:519-24.

15 Kjeldsen AD, Oxhøj H, Andersen PE, et al. Pulmonary arteriovenous malformations: screening procedures and pulmonary angiography in patients with hereditary hemorrhagic telangiectasia. Chest patients with hereditar
1999:1 16:432-9.

16 Piantanida M, Buscarini E, Dellavecchia C, et al. Hereditary haemorrhagic telangiectasia with extensive liver involvement is no caused by either HHT1 or HHT2. J Med Genet 1996;33:441-3.

17 McDonald J, Miller FJ, Hallam SE, et al. Clinical manifestations in a large hereditary hemorrhagic telangiectasia (HHT) type 2 kindred. Am Med Genet 2000;93:320-7.

18 Fulbright RK, Chaloupka JC, Putman CM, et al. MR of hereditary hemorrhagic telangiectasia: prevalence and spectrum of cerebrovascular malformations. Am J Neuroradiology 1998;19:477-84.

19 Feinstein J, Moore P, Rosenthal D, et al. Comparison of contrast echocardiography versus cardiac catheterisation for detection of pulmonary arteriovenous malformations. Am J Cardiol 2002;89:281-5.

20 Plauchu H, de Chadarévian J-P, Bideau A, et al. Age-related profile of hereditary hemorrhagic telangiectasia in an epidemiologically recruited population. Am J Med Genet 1989:32:291-7.

21 Porteous MEM, Burn J, Proctor SJ. Hereditary haemorrhagic telangiectasia: a clinical analysis. J Med Genet 1992:29.527-30.

22 Shovlin CL, Hughes JMB, Tuddenham EGD, et al. A gene for hereditary haemorrhagic telangiectasia maps to chromosome 9q3. Nat Genet 1994;6:205-9. 
23 Shovlin CL, Guttmacher AE, Buscarini E, et al. Diagnostic criteria for hereditary haemorrhagic telangiectasia (Rendu-Osler-Weber syndrome). Am J Med Genet 2000 91:66-7.

24 Aassar OS, Friedman CM, White RI. The natural history of epistaxis in Aassar OS, Friedman $C M$, White RI. The natural history of epistaxis in
hereditary hemorrhagic telangiectasia. Laryngoscope 1991;101:97780.

25 Lennox $\mathbf{P}$, Harries $M$, Lund $V$, et al. A retrospective study of the role of the argon laser in the management of epistaxis secondary to hereditary hemorrhagic telangiectasia. J Laryngol Otol 1997;111:34-7.

26 Shapshay S, Oliver P. Treatment of hereditary hemorrhagic telangiectasia by Nd-YAG laser photocoagulation. Laryngoscope 1984:94:1554-6.

27 Ulso C, Vase P, Stoksted P. Long term results of dermatoplasty in the treatment of hereditary hemorrhagic telangiectasia. J Laryngol Otol 1983;97:223-6.

28 Lund V, Howard D. Closure of the nasal cavities in the treatment of refractory hereditary haemorrhagic telangiectasia. J Laryngol Otol 1997; 111:30-3

29 Kjeldsen A, Kjeldsen J. Gastrointestinal bleeding in patients with hereditary hemorrhagic telangiectasia. Am J Gastroenterol 2000:95:415-8.

30 Sargeant I, Loizou L, Rampton D, et al. Laser ablation of upper gastrointestinal vascular ectasias: long term results. Gut 1993;34:470-5.

31 Van Cutsem E, Rutgeerts P, Vantrappen G. Treatment of bleeding gastrointestinal vascular malformations with oestrogen-progesterone. Lancet 1990;335:953-5.

32 Shovlin CL, Letarte M. Hereditary haemorrhagic telangiectasia and pulmonary arteriovenous malformations: issues in clinical management and review of pathogenic mechanisms. Thorax 1999;54:714-29.

33 Sagara K, Miyazono N, Inove H, et al. Recanalization after coil embolotherapy of pulmonary arteriovenous malformations: study of long term outcome and mechanism for recanalization. Am J Roentgeno 1998;170:727-30

34 Graf CJ, Perrett GE, Torner JC. Bleeding from cerebral arteriovenous malformations as part of their natural history. J Neurosurg 1983;58:331-7.

35 Perret G, Nishioka H. Arteriovenous malformations: an analysis of 545 cases of cranio-cerebral arteriovenous malformations and fistulae reported to the cooperative study. In: Sahs A, Perret G, Locksley H, et al, eds. Intracranial aneurysms and subarachnoid haemorrhage: a eds. Intracranial aneurysms and subarachnoid haemorrhage: a

36 Garcia-Tsao G, Korzenik JR, Young L, et al. Liver disease in patients with hereditary hemorrhagic telangiectasia. N Engl J Med 2000;343:931-6

37 Caselitz M, Wagner S, Chavan A, et al. Clinical outcome of transfemoral embolisation in patients with arteriovenous malformations of the liver in hereditary haemorrhagic telangiectasia (Weber-Rendu-Osler disease). Gut 1998;42:123-6.

38 Buscarini E, Buscarini L, Civardi G, et al. Hepatic vascular malformations in hereditary hemorrhagic telangiectasia: imaging indings. Am J Radiol 1994; 163:1 105-10.

39 Miller F, Whiting J, Korzenik J, et al. Caution with use of hepatic embolization in the treatment of hereditary hemorrhagic telangiectasia. Radiology 2000;213:928-30.

40 Boillot O, Bianco F, Viale J-P, et al. Liver transplantation resolves the hyperdynamic circulation in hereditary hemorrhagic telangiectasia with hepatic involvement. Gastroenterology 1999;116:187-92.
41 Shovlin CL, Winstock AR, Peters AM, et al. Medical complications of pregnancy in hereditary haemorrhagic telangiectasia. Q J Med 1995:88:879-87.

42 Gershon A, Faughnan M, Chon K, et al. Transcatheter embolotherapy of maternal pulmonary arteriovenous malformations during pregnancy. Chest 2001;119:470-7.

43 Willemse RB, Mager JJ, Westermann CJJ, et al. Bleeding risk of cerebrovascular malformations in hereditary haemorrhagic telangiectasia. J Neurosurg 2000;92:779-84.

44 Sabba C, Gallitelli M, Palasciano G. Efficacy of unusually high doses of tranexamic acid for the treatment of epistaxis in hereditary hemorrhagic telangiectasia. N Engl J Med 2001;345:926.

45 Saba HI, Morelli GA, Logrono LA. Treatment of bleeding in hereditary hemorrhagic telangiectasia with aminocaproic acid. N Engl J Med 1994:330: 1789-90.

46 Shovlin CL, Begbie ME. Venous thromboembolism and endothelial dysfunction in hereditary haemorrhagic telangiectasia $(\mathrm{HHT}$, Osler-Weber-Rendu syndrome). Thorax 2001;56:iii79.

47 Trembath R, Thomson JR, Machado RD, et al. Clinical and molecular features of pulmonary hypertension in hereditary hemorrhagic telangiectasia. N Engl J Med 2001;345:325-34.

48 Wallace GMF, Shovlin CL. A hereditary haemorrhagic telangiectasia family with pulmonary involvement is unlinked to the known HHT genes, endoglin and ALK-1. Thorax 2000;55:685-90.

49 Bourdeau A, Dumont DJ, Letarte M. A murine model of hereditary hemorrhagic telangiectasia. J Clin Invest 1999;104:1343-51.

50 Cymerman $U$, Vera S, Pece-Barbara N, et al. Identification of hereditary hemorrhagic telangiectasia type I in newborns by protein expression and mutation analysis of endoglin. Pediatr Res 2000;47:24-35.

51 Abdalla S, Pece-Barbara N, Vera S, et al. Analysis of ALK-1 and endoglin in newborns from families with hereditary hemorrhagic telangiectasia type 2. Hum Mol Genet 2000;9:1227-37.

52 Bourdeau A, Cymerman U, Paquet $M-E$, et al. Endoglin expression is reduced on normal vessels but still detectable in arteriovenous malformations of patients with hereditary haemorrhagic telangiectasia type I. Am J Pathol 2000;156:911-23.

53 Heldin C-H, Miyazono K, ten Dijke P. TGF- $\beta$ signalling from cell membrane to nucleus through SMAD proteins. Nature 1997;390:465-71.

\section{ANSWERS}

Q1. (A) F (one in 8000), (B) F (needs pulmonary AVM screening), (C) F, (D) T, (E) T. Q2. (A) F, (B) T, (C) F, (D) F (only suspected HHT), (E) F. Q3. (A) T, (B) T, (C) T, (D) T, (E) T. Q4. (A) F, (B) T, (C) do not know; subject remains topic for debate, (D) F, (E) F, though there may be special circumstances, such as epidural analgesia when this might be considered. Q5. (A) T, (B) F, (C) F, (D) F (pregnancy precipitates pulmonary AVM development), (E) F 